\title{
Grupo virtual de apoio aos cuidadores familiares de idosos com demência no contexto da COVID-19 1
}

\author{
Virtual support group for family caregivers of elderly people with dementia \\ in the COVID-19 scenery
}

Emanuela Bezerra Torres Mattos ${ }^{a}$ (D), Isabela da Costa Francisco ${ }^{a}$ (D), Gabrielle Christine Pereira ${ }^{a}$ (D), Marcia Maria Pires Camargo Novelli ${ }^{a}$ (D)

${ }^{a}$ Universidade Federal de São Paulo - UNIFESP, São Paulo, SP, Brasil.

Como citar: Mattos, E. B. T., Francisco, I. C., Pereira, G. C., \& Novelli, M. M. P. C. (2021). Grupo virtual de apoio aos cuidadores familiares de idosos com demência no contexto da COVID-19. Cadernos Brasileiros de Terapia Ocupacional, 29, e2882. https://doi.org/10.1590/2526-8910.ctoRE2201

\begin{abstract}
$\underline{\text { Resumo }}$
Introduçáo: $\mathrm{O}$ estado físico, mental e social dos cuidadores familiares e as suas demandas no cuidado têm sido amplamente esquecidos. Este fato não tem sido diferente durante a pandemia da COVID-19. Portanto, o cuidado domiciliar precisará de atualizaçóes para esse novo contexto da pandemia, priorizando fornecer orientaçóes personalizadas para os cuidadores familiares. Objetivos: Minimizar o impacto sobre a saúde mental dos cuidadores familiares de pessoas com demência por meio do grupo virtual de apoio aos cuidadores familiares. Método: A pesquisa foi desenvolvida a partir da realizaçáo de grupos de apoio aos cuidadores familiares na demência no formato virtual. Os encontros foram semanais, com duração de 2 horas, e os temas eram trabalhados a partir das demandas do grupo. Todos os encontros foram gravados, transcritos e analisados por meio da análise de conteúdo temática. Resultados: Nos 8 encontros, participaram 10 cuidadores familiares e foram identificadas 5 categorias temáticas: a tecnologia; a rotina na pandemia da COVID-19; alteraçôes de comportamento e sua relação com a saúde mental do cuidador; a rede de apoio como um marcador de saúde; e a nova forma de realizar as atividades significativas. Conclusáo: $\mathrm{O}$ grupo de apoio no formato virtual se mostrou como uma ferramenta potente para o acesso à informação e para orientaçóes em relação à demência, sobre o cuidado ao familiar e açóes voltadas para o autocuidado do cuidador, com impacto no seu estado emocional e bem-estar, minimizando o sentimento de isolamento social durante a pandemia da COVID-19.
\end{abstract}

\footnotetext{
${ }^{1}$ Este trabalho é resultado de um projeto de extensão intitulado Grupo Mente Aberta de suporte e apoio aos cuidadores familiares de pessoas com demência, oferecido pela Universidade Federal de São Paulo, Campus Baixada Santista. A contribuição é original e inédita, e não foi submetida a nenhum outro periódico. Foram respeitados todos os procedimentos éticos necessários na análise da intervenção.
} 
Palavras-chave: Envelhecimento, Demência, Cuidadores, Terapia Ocupacional.

\begin{abstract}
Introduction: The physical, mental and social status of family caregivers and their care demands have been largely overlooked. This fact has been no different during the COVID-19 pandemic. Therefore, home care will need updates for this new pandemic context, prioritizing the provision of personalized guidance for family caregivers. Objective: To minimize the impact on the mental health of family caregivers of people with dementia through the virtual support group for family caregivers. Method: The research was developed from the performance of support groups for family caregivers in dementia in the virtual format. The meetings were weekly, lasting 2 hours and the themes were worked out according to the group's demands. All meetings were recorded, transcribed, and analyzed using thematic content analysis. Results: In the 8 meetings, 10 family caregivers participated and 5 thematic categories were identified: technology; the routine in the COVID-19 pandemic; behavioral changes and their relationship with the caregiver's mental health; the support network as a health marker; and the new way of carrying out meaningful activities. Conclusion: The support group in the virtual format proved to be a powerful tool for accessing information and guidance concerning dementia, about family care and actions aimed at the caregiver's self-care, with an impact on their emotional state and well-being, minimizing the feeling of social isolation during the COVID-19 pandemic.
\end{abstract}

Keywords: Aging, Dementia, Caregivers, Occupational Therapy.

\title{
Introduçáo
}

A COVID-19 chega ao Brasil e possui seu primeiro caso confirmado em 26 de fevereiro de 2020, em São Paulo (Ministério da Saúde, 2020). Como medida de prevenção do alastramento da doença e da curva de contágio, as autoridades determinaram o distanciamento físico como uma prática eficaz e necessária para frear o aumento de casos no país (Organização Pan-Americana da Saúde, 2020).

Em geral, os idosos são mais vulneráveis diante de desastres naturais e foi possível identificar essa vulnerabilidade durante a pandemia da COVID-19 (Kontoagelos et al., 2020), pois traz maior risco de morte em idosos com comorbidades, sendo um duplo golpe para pessoas que vivem com demência e seus familiares e/ou cuidadores (Bianchetti et al., 2020; Huali et al., 2020).

A demência, definida como Transtorno Neurocognitivo Maior (TNM), também tem sido um importante problema de saúde pública global, com desafios sociais e médicos (American Psychiatric Association, 2014; Engedal \& Laks, 2016). As síndromes demenciais são diagnosticadas a partir de um declínio cognitivo (atenção; funcionamento executivo; aprendizado e memória; linguagem; percepção motora e cognição social) em relação a um nível de desempenho funcional e ocupacional anterior, reforçado pelo relato do próprio indivíduo, de um informante ou pela observação clínica ${ }^{6}$. Em todo mundo, estima-se que o número de pessoas com 
demência alcançará 65,7 milhóes em 2030 e 115,4 milhóes em 2050. Nesses respectivos anos, essa proporção chegará a $63 \%$ e $71 \%$ nos países de baixa e média renda (Prince et al., 2013).

Neste período do distanciamento físico, pessoas com demência merecem especial atenção, pois, além de sua necessidade de auxílio e/ou supervisão nas atividades de vida diária, a depender do grau de comprometimento, passam a depender de outros para os cuidados necessários para a prevenção de contaminação do coronavírus, como nos seguintes casos: uso da máscara, assepsia das mãos e distanciamento social. Tal fato ocorre devido à sua dificuldade de reter ou processar novas informaçóes, o que implica em maiores riscos de contrair a doença (Huali et al., 2020; Schapira et al., 2020). Muitos desses idosos estão na dependência de terceiros para que tenham a garantia de acesso à comida, à medicação, além de outras demandas (Armitage \& Nellums, 2020).

O curso gradual, progressivo e irreversível das demências compromete não somente a pessoa com demência, mas também seus cuidadores e sua família (Levy \& Burns, 2011). Estes, na grande maioria, são mulheres, idosas e sofrem significativa sobrecarga e estresse, com tendência ao aumento gradual das demandas e responsabilidades na medida em que a doença evolui, o que resulta em piores condiçốes físicas e psicológicas (Mattos \& Kovács, 2020), e implica maior susceptibilidade ao abuso de idosos (Holmes et al., 2020), o que pode ser exacerbado durante o distanciamento físico.

Segundo Chan et al. (2020), o estado físico, mental e social dos cuidadores familiares e as suas demandas no cuidado têm sido amplamente esquecidos. Este fato não tem sido diferente durante a pandemia da COVID-19, na qual se observa a falta de conhecimento sobre a situação devido à dificuldade no acesso às informaçóes, à assistência e à orientaçáo médica. Portanto, o cuidado domiciliar precisará de atualizaçóes para esse novo contexto da pandemia, priorizando fornecer orientaçóes personalizadas para os cuidadores familiares.

Assim, a Alzheimer Disease International (2019) chama atenção para a urgência de implementação de redes de apoio psicossocial e suporte gratuito no intuito de minimizar o impacto sobre a saúde mental, tanto das pessoas com demência quanto de seus cuidadores, para reduzir o estresse, utilizando de meios virtuais de atendimento. Dessa forma, o presente estudo teve como objetivo minimizar o impacto sobre a saúde mental dos cuidadores familiares de pessoas com demência, por meio do grupo virtual de apoio aos cuidadores familiares.

\section{Método}

A pesquisa foi desenvolvida a partir da realização de oito encontros do grupo de apoio de suporte aos cuidadores familiares de pessoas idosas com demência, no formato virtual, diante do cenário da pandemia da COVID-19.

O estudo foi submetido e aprovado pelo Comitê de Ética em Pesquisa com seres humanos da Universidade Federal de Sáo Paulo, sob o parecer $n^{\circ}$ 0709/2018. Todos os participantes, em seu primeiro encontro, receberam, junto com o link de participação da reunião, o link do Termo de Consentimento Livre e Esclarecido (TCLE), de acordo com 
a Resolução no 466/2012, para ciência e explicitação dos objetivos da pesquisa, bem como os princípios éticos.

O grupo de apoio e suporte aos cuidadores foi oferecido diante da pandemia da COVID-19 no formato virtual, devido à crescente procura dos cuidadores por apoio e orientação dos profissionais do Serviço de Atenção ao Envelhecimento Cognitivo (SAEC) da Universidade Federal de São Paulo/Campus Baixada Santista, em relação às demandas de cuidado da pessoa com demência e de autocuidado do cuidador familiar.

Os encontros com o grupo foram realizados pela plataforma virtual via Google Meets. Para isso, os cuidadores receberam o link da reunião, via WhatsApp, com dia e horário préestabelecido. Os encontros foram semanais, com 2 horas de duração, e ocorreram no período de 20/05/2020 a 08/07/2020.

Os critérios de inclusão dos cuidadores foram: exercer o papel de cuidador familiar no mínimo há 6 meses; ser cuidador(a) familiar de idoso com demência e ter interesse e disponibilidade para participar dos encontros. Como critério de exclusão, foi proposto: ser cuidador profissional. No intuito de garantir o princípio ético de sigilo e não identificação, todos os cuidadores foram identificados com a sigla $C$, que corresponde a cuidador, seguido de numeral de 1 a 10, de acordo com a ordem das falas apresentadas.

Os encontros foram delineados de forma que os próprios cuidadores apontaram os temas que gostariam de abordar e discutir no formato de rodas de conversa. Os terapeutas ocupacionais, enquanto coordenadores do grupo, alinhavaram os pontos expressos pelos participantes aos pontos centrais no cuidado do outro e de si próprio. Segundo Morin (2003), as rodas de conversa, do ponto de vista da complexidade, dão liga a questôes aparentemente separadas, a fim de que partes e o todo sejam captados como facetas de um mesmo objeto, que em si mesmo é complexo e contraditório, duro e utópico: "os condicionantes sociais e a realidade a ser (re)construída”.

Nos encontros, as questôes centrais das discussões foram: apresentação dos participantes (para coleta de dados sociodemográficos, informaçôes gerais em relação à saúde da pessoa com demência e do seu cuidador) e outras, conforme as demandas dos cuidadores (contexto do cuidado, impacto da pandemia, redes de suporte e o acesso à informação e à orientação).

Todos os encontros foram gravados, transcritos e, posteriormente, analisados por meio da análise de conteúdo temática proposta por Minayo (2015). O método pressupóe a leitura compreensiva do material selecionado para a impregnação das falas, a exploração do material no sentido de alcançar do revelado ao velado e elaboração de uma síntese interpretativa articulando temas centrais. A partir da análise das falas emergiram seis categorias temáticas que serão discutidas nos resultados a seguir.

\section{Resultados e Discussáo}

A Tabela 1 apresenta os resultados dos dados sociodemográficos dos cuidadores familiares participantes do grupo de apoio. 
Tabela 1. Dados sociodemográficos dos cuidadores familiares participantes.

\begin{tabular}{ccccc}
\hline Participantes & $\begin{array}{c}\text { Idade } \\
(\mathbf{e m} \text { anos })\end{array}$ & Sexo & Estado Civil & Grau de Parentesco \\
\hline C1 & 75 & Feminino & Casada & Cônjuge \\
\hline C2 & 68 & Feminino & Casada & Cônjuge \\
\hline C3 & 70 & Masculino & Casado & Cônjuge \\
\hline C4 & 47 & Feminino & Divorciada & Filha \\
\hline C5 & 20 & Feminino & Solteira & Neta \\
\hline C6 & 49 & Masculino & Solteiro & Filho \\
\hline C7 & 63 & Feminino & Solteira & Filha \\
\hline C8 & 51 & Masculino & Casado & Filho \\
\hline C9 & 55 & Feminino & Casada & Filha \\
\hline C10 & 61 & Feminino & Solteira & Filha \\
\hline
\end{tabular}

Fonte: Elaboração própria

Ao longo dos oito encontros, participaram, aproximadamente, seis cuidadores familiares por grupo, sendo que o total de participantes do estudo foram 10 cuidadores familiares. Destes, $70 \%$ eram do sexo feminino. O grau de parentesco com maior representação foi filho(a), com 60\%, seguido de cônjuges, com 30\%. A idade dos cuidadores variou entre 20 e 75 anos.

O cuidador C4 recebia suporte da família no cuidado do idoso com demência, enquanto o cuidador $\mathrm{C} 7$ recebia suporte no cuidado por meio de cuidador profissional. Os demais não contaram com rede de suporte familiar, nem de cuidadores profissionais ou da própria comunidade durante esse período. Os cuidadores C4 e C10 cuidavam de ambos os pais, sendo que uma cuidava da mãe com demência e do pai com doença de Parkinson, e a outra cuidava da máe com demência e do pai com mais de 90 anos, respectivamente. Apenas o cuidador C8 não residia com seu familiar com demência e a cuidadora C5 mudou para a casa da avó para auxiliar nos cuidados durante o período da pandemia da COVID19.

Cada encontro foi iniciado com o questionamento sobre a rotina dos cuidadores, na qual eram identificadas as demandas e todos os participantes tinham a oportunidade de falar sobre os temas abordados de acordo com o interesse do grupo. A partir das demandas apresentadas, eram realizadas açóes informativas sobre os cuidados que permeiam a demência e/ou rodas de conversa sobre os temas abordados. Com base nas transcriçóes e análises das falas, foram identificadas 5 categorias temáticas, apresentadas e discutidas a seguir.

\section{1a) A tecnologia: avanços e desafios}

A chegada da COVID-19 e a necessidade do afastamento social ocasionaram uma série de adequaçóes e reorganizaçóes do cotidiano dos indivíduos. Como dito por Schapira et al. (2020), o estar em casa nos dias de hoje não se compara ao estar em casa antes da pandemia e a interação com o mundo afora se propóe a ser mediada pela tecnologia. São as mensagens de WhatsApp, as reunióes, aulas, lives pelas plataformas de vídeoconferência que atravessam a rotina na tentativa de conciliar as demandas e as obrigaçóes. Além das dificuldades 
propriamente ditas com o uso das diversas tecnologias, deparou-se também com as limitaçóes advindas da utilizaçáo de aparelhos de celular e/ou de equipamentos, como computadores mais antigos e em funçóes anteriormente não exploradas (uso de videochamada), e também do acesso à internet de boa qualidade.

Os encontros virtuais apontaram algumas das dificuldades diante da busca por apoio on-line, conforme os relatos a seguir:

Eu me confundo um pouco aqui com essas coisas. Estou aparecendo agora?" e "como é que é? É que corta muito, eu não estou entendendo direito o que vocês falam, está picotando muito. (C1, esposa, 75 anos).

Essa internet está me deixando doida hoje. Aqui eu não estou ouvindo mais vocês. (C10, filha, 61 anos).

Além disso, foi possível perceber como o ambiente de realização da atividade afeta diretamente em seu resultado. $\mathrm{O}$ grupo de apoio no formato virtual afetou o nível de envolvimento, atenção e de tempo para si, visto que muitos dos cuidadores dividem o mesmo espaço que seus familiares com demência. A dificuldade em manter um espaço de privacidade para suas falas e necessidades foram observadas.

Assim, ele tem um esquecimento, mas é normal... Estou em reuniäo [respondendo alguém de fundo]. É que ele está aqui na sala, ele quer saber o que é que eu estou falando e por que que eu estou falando. (C2, esposa, 68 anos).

$\mathrm{O}$ atravessamento nas atividades de rotina e sobreposição de tarefas fez com que alguns não conseguissem se organizar previamente para a participação efetiva no grupo.

Ainda assim, esses grupos são de extrema importância para cuidadores familiares diante do distanciamento físico. Segundo Camacho et al. (2020), o suporte informal aos cuidadores familiares, por meio das plataformas remotas no período de pandemia, é fundamental devido à necessidade de orientação singular aos cuidados com idosos com comprometimentos cognitivos. Mas, também, não somente a eles, pois é primordial fornecer um espaço de cuidado e escuta ativa a esses cuidadores familiares que lidam constantemente com os desafios de cuidado no distanciamento físico em que seus níveis de sobrecarga e estresse estão mais elevados.

Ao se estimular a participação dos cuidadores familiares nesses espaços virtuais, permitese o acesso à informação e à orientação quanto às demandas de cuidado na demência, ao mesmo tempo em que favorece a troca de experiências e saberes, espaço de escuta e acolhimento (Camacho et al., 2020).

\section{2a) A realidade da rotina na pandemia da COVID-19}

O estímulo da pessoa com demência na quarentena, a sobreposição de tarefas, o medo da contaminação de si e do outro, a maior vulnerabilidade de seus familiares diante da pandemia da COVID-19 fazem parte da rotina diária dos cuidadores. Segundo o estudo de Bezerra et al. (2020), sobre os fatores associados ao comportamento da população durante o distanciamento físico na pandemia da COVID-19, para 39\% dos entrevistados, o convívio social é o principal aspecto que está sendo afetado pelo distanciamento. 
Brooks et al. (2020), em seu estudo sobre o impacto psicológico do distanciamento físico, também aponta a perda da rotina como um importante fator estressor, sugerindo a necessidade da criação de redes de suporte e de comunicação específicas para minimizar esses problemas.

Nesse processo de ruptura, a questão da sobreposição de tarefas para o cuidador familiar se apresentou como uma importante questão a ser acompanhada. Pessoas que possuem a necessidade de realizar a atividade de cuidado dentro de casa não estáo limitadas apenas a essas tarefas. Grande parte dos cuidadores lidam com seus familiares com comprometimentos cognitivos, como no caso das demências, que requerem cuidado em tempo integral, incluindo a manutenção da saúde e o cuidado suplementar, por exemplo, higienização dos alimentos e das vestimentas, cuidados com a higiene das mãos, uso e cuidados com a máscara, durante o período de pandemia da COVID-19 (Chan et al., 2020). Soma-se a isso as necessidades de realização de outras atividades que compóem a rotina desses cuidadores, como: cuidar de outras pessoas dependentes, realizar atividades de trabalho e de cuidados com a casa, da família e de si sem poder receber a ajuda de familiares, que até então colaboravam com o cuidado, o que gerou uma sobrecarga ainda maior. Uma cuidadora demonstra a dificuldade em realizar as atividades de cuidado sozinha durante esse período:

A minha filha [...] ela trabalha o dia todo, não está nem aí. Mas meu filho, ele ajuda bastante, só que com a pandemia ele alugou uma casa no interior. Eles costumam levar a gente, mas agora não dá mais para levar meu marido junto! Agora eles vão para lá e eu fico aqui. (C1, esposa, 75 anos).

Já um cuidador se queixou a respeito da inclusão de novas atividades e cuidados exigidos e necessários durante o período da pandemia da COVID-19, que teve um impacto na sobreposição de tarefas:

Hoje foi dia de feira então você imagina? Todo o preparo para sair, todo o preparo para entrar, depois tem que lavar tudo, limpar tudo. E eu comprei frango ai tem que limpar para congelar, lavei roupa... um monte de coisas. (C3, esposo, 70 anos).

Chan et al. (2020) identificou que cuidadores familiares não possuíam conhecimento e informaçóes adequadas sobre os deveres do cuidado da saúde, o que aumentou o estresse psicológico. Nessa pesquisa, ficou evidente a falta de experiência e formação para um cuidado adequado do idoso em domicílio, na qual, muitas vezes, o contexto ambiental não é levado em consideração, assim como a falta de equipamentos e materiais necessários para fornecer o cuidado.

O relato a seguir mostra como a questão da sobreposição de tarefas veio à tona durante o período de distanciamento físico:

Tive que dispensar a moça que ajudava aqui em casa, então é difícil porque eu tenho que cuidar da casa, faço comida, e minha mãe, ela está bem, ela faz as coisas, ajuda, mas tem coisas que ela acaba esquecendo. Com essa quarentena, ela estava acostumada a todo dia dar uma caminhada aqui no Rebouças e agora ela náo está 
podendo sair de casa [...] está difícil porque minha mãe ainda está com muitas manias e agora com a quarentena acabou acentuando mais. (C4, filha, 47 anos).

Os idosos são mais vulneráveis aos desastres naturais e crises, especialmente aquelas que possuem algum tipo de comprometimento, como no caso das demências. No contexto da pandemia da COVID-19, idosos com comprometimento cognitivo têm uma maior chance de contaminação por não lembrarem de seguir as orientaçôes recomendadas pela Organização Mundial de Saúde. Idosos nessas condiçôes possuem maiores dificuldades para aderir às novas estratégias de cuidado, como usar máscaras, lavar as mãos com frequência, fazer uso do álcool em gel e entender as recomendações de saúde pública (Huali et al., 2020; Kontoagelos et al., 2020).

Nosso grupo identificou nas falas desses cuidadores que o esquecimento comum à demência tem se tornado um desafio diário em suas atividades de cuidado.

O correio [chegou], tive que ir lá buscar porque se ela pega, não lava a mão, não passa um álcool. Então vou eu e depois eu tomo cuidado, porque se deixar é a mesma coisa que nada. Então eu sabendo disso, eu afasto o máximo possivel. Por exemplo, coloquei um cadeado lá na caixa de correio para ela não pegar nada. Ai eu vou lá e pego. Então eu estou tentando fazer de tudo para ter um minimo contato com fora. Às vezes saio eu, às vezes nós só saímos juntos para ela ir ao médico ou fazer exames, só. O resto ela fica em casa, saio eu porque ela coloca a mão em todo lugar, ela não tem consciência do perigo que a gente está vivendo. (C3, marido, 70 anos).

A garantia da saúde de seus familiares com demência se torna um fator estressante na rotina de cuidado. $\mathrm{O}$ medo da contaminaçáo de si e do outro tem se mostrado como um fator de sobrecarga na saúde mental desses cuidadores familiares. Estudo de Brooks et al. (2020) sobre o impacto psicológico do distanciamento físico relatou que cuidadores temem sobre sua própria saúde e medo de infectar outras pessoas. A preocupação estava relacionada à percepção e observação de algum sintoma físico comum na doença que pudesse contaminar seus familiares. A fala a seguir corrobora os achados.

Eu já chego em casa preocupada, porque eu tenho que lavar as coisas, tomo um banho, tiro a máscara. Aí já vou lavar as coisas tudo certinho para eles não terem que pegar alguma coisa e náo correr o risco de se contaminar. Eu já fico tensa, sabe?! Por sair e acabar passando alguma coisa. Que nem domingo passado que eu fui para o prontosocorro. Graças a Deus não tinha ninguém! Eu o levei no APAS e foi tranquilo, mas eu já fiquei preocupada, olhando toda hora, passando álcool gel, coloquei 2 máscaras. (C4, filha, 47 anos).

A pandemia da COVID-19 tem imposto uma série de restriçóes e novas configuraçóes sociais, nas quais a família desses idosos possui papel fundamental nas açôes de apoio e na melhoria da sua qualidade de vida, visando diminuir seus impactos (Camacho et al., 2020). Jiménez et al. (2019) apontaram que cuidar de uma pessoa com demência em tempos de distanciamento físico trouxe mais desafios do que para a populaçáo no geral, diante da necessidade de buscar orientaçóes sobre o que e como fazer para implementar atividades de estimulação cognitiva e funcional, acessar as redes 
sociais para minimizar o distanciamento social, realizar teleconsultas, fazer buscas por apoio, participar de outras tarefas significativas adequadas ao formato virtual, entre outras. Esse contexto trouxe a necessidade da readequação desse cotidiano, segundo apontou a cuidadora a seguir.

Está um pouco difícil, porque desde que começou a quarentena ela perdeu a rotina que ela tinha. Ela ia na academia com meu avô, ela sempre saía todo dia, ia visitar minha tia, então desde o ano passado ela tinha toda uma rotina que foi quebrada. Então eu sinto que desde que começou a pandemia, a demência dela deslanchou um pouco. (C5, neta, 20 anos).

Um filho cuidador desenvolveu atividades de estimulação com a mãe, por meio de pintura de desenhos, colagem, atividades de escrita, leitura e música. Ele referiu inserir o planejamento do aniversário dela para estimular a participação no processo de estimulação cognitiva que envolveu desde a escolha da decoração e do cardápio até a lista de convidados.

Eu falei "mãe, a gente vai chamar quem? Vamos fazer um convite, vamos elaborar e começar com as pessoas da familia" e ela começou a enumerar aquelas pessoas. [...] "Agora nós vamos chamar quem dos vizinhos?" e ela disse "Ah, nós vamos chamar aquele..." e eu perguntava "Qual o nome dele?". Algumas coisas eu via que ela tinha dificuldade, ai eu ajudava. (C6, filho, 49 anos).

Outro filho relatou a necessidade de inserir atividades no cotidiano de seu pai durante o distanciamento físico:

Teve um problema no telefone da minha mãe. Eu mesmo troquei as tomadas e ele [meu pai] me ajudou. Ele ficava procurando as ferramentas com a chave. Então isso dai ocupou praticamente 2 dias lá a tarde toda. Então eu também procuro envolver ele em algumas coisas que não gere risco para ele, mas eu costumo colocar ele para se sentir útil e ele faz bem, isso ajuda bastante. (C8, filho, 51 anos).

\section{3a) Alteraçóes de comportamento e sua relaçáo com a saúde mental do cuidador}

Os sintomas comportamentais e psicológicos (SCPD) comumente associados às demências são marcadores de maior sobrecarga e estresse do cuidador e elevam tanto a prevalência de institucionalizaçóes precoces de idosos quanto o maior nível de violência física e psicológica (Caramelli \& Bottino, 2007; Júnior \& Souza, 2017). Dentre os principais SCPD, estão a depressáo, apatia, alucinaçóes, delírios, agitação, distúrbios do sono, distúrbios alimentares, desinibição e comportamento motor aberrante, cuja frequência tende a aumentar conforme a progressão da demência (Selbaek et al., 2007; Lyketsos et al., 2011).

Com o distanciamento físico e a alteração brusca da rotina, é comum que aqueles idosos com demência, que já apresentam SCPD, tenham esses comportamentos acentuados. Pode ser comum também que aqueles que não manifestaram SCPD passem a apresentar tais comportamentos. Esses sintomas influenciam diretamente e negativamente no ambiente físico e social e afetam a qualidade do cuidado, visto que aumentam o estresse do cuidador 
(Allegri et al., 2006; Cuffaro et al., 2020; Kontoagelos et al., 2020). O aparecimento ou exacerbamento desses sintomas durante o distanciamento físico foram comuns em algumas das falas de cuidadores:

Na verdade, as tarefas não são cansativas, o que me estressa mais é a repetição constante das mesmas perguntas e a "arrumação" das coisas que ela faz porque na verdade desarruma as coisas que eu tinha arrumado (risos). (C3, esposo, 70 anos).

O pior periodo é à noite; dormimos no mesmo quarto. Esse ano ela está tendo muitos episódios de agitação e passamos muitas noites sem dormir ou mal dormidas, dificilmente consigo dormir durante o dia. (C7, filha, 63 anos).

C4 (filha, 47 anos) demonstrou que os sintomas comportamentais de seu pai foram exacerbados com o distanciamento físico.

Às 17:00 horas começa a confusão. Já não quer tomar o remédio e pede para ir para casa. Quando assistimos televisão e começa a novela das 18:00 horas tem que mudar de canal, porque ele acha que a novela está dentro de casa, que os personagens estão aqui. Então esse horário é bem complicado. Hoje ele está bem confuso, porque ele quer sair. Eu falo que não pode sair por conta do COVID. (C4, filha, 47 anos).

Diante da manifestação desses sintomas, aumentaram as demandas por orientação quanto ao manejo desses SPCD. O grupo trouxe a possibilidade de orientação, informação e discussão sobre o porquê de tais alteraçôes se acentuarem no período de distanciamento e colaborou para que os próprios cuidadores pudessem implementar estratégias práticas de manejo e, assim, minimizar o estresse e a sobrecarga. Nossos participantes compartilharam sobre os efeitos positivos dessas orientaçóes e referiram se sentir mais bem orientados para tentar lidar com as situaçóes de maneira mais leve.

Mas o que para mim esse exercício acabou ajudando muito foi que também acabei exercitando a minha paciência [...] eu comecei a perceber que dava para ter mais paciência com a coisa [...] deu uma boa melhorada. Deu uma sintonizada melhor. (C3, esposo, 70 anos).

Essa semana, mediante a outra reunião que a gente teve, eu tentei colocar mais em ação a situação de sair do momento de conflito, respirar fundo e tentar voltar novamente à situaçâo. Hoje mesmo eu fiz isso. (C6, filho, 49 anos).

Relatos como esses evidenciam a importância desses espaços virtuais como uma rede de suporte, tanto para a orientaçáo quanto para o acolhimento e escuta desses cuidadores que vivenciam muitas situaçóes desgastantes durante o seu cotidiano.

\section{4a) A rede de apoio como um marcador de saúde}

Mudanças na rotina, como as vivenciadas atualmente, exigem uma capacidade de resiliência para adaptação à nova realidade, pois, uma vez que se mantêm por longos períodos, expóem os indivíduos a maiores riscos de desenvolver sintomas depressivos e de ansiedade (Armitage \& Nellums, 2020; Kontoagelos et al., 2020). Portanto, o suporte com 
relação à saúde mental foi definido como serviço essencial durante este período (D’Agostino et al., 2020).

A pandemia levou a uma dependência sem precedentes de cuidados domiciliares, resultando em novos desafios durante o processo de cuidado, pois, como consequência da mudança nos hábitos de vida e restriçóes, temos o sentimento de solidão (Holmes et al., 2020). Essa realidade nos instiga a refletir sobre as particularidades e dificuldade enfrentadas pelos cuidadores durante esse período. Ficou evidente nos relatos que a participação no grupo de apoio e/ou suporte foi para alguns a única possibilidade de minimizar o sentimento de solidão.

Na verdade, mesmo se não for isolamento somos só nós 2, nós não temos filhos [...] então não tem assim grandes conversas, [...] e eu não tenho com quem conversar. (C3, esposo, 70 anos).

Durante a pandemia, aqueles cuidadores que puderam contar com uma ampla rede de suporte social, como o revezamento entre familiares e/ou presença de cuidador profissional, por exemplo, não referiram sentir a necessidade de participação no grupo para minimizar o sentimento de solidão. Porém, na grande maioria, os participantes do grupo tinham empobrecimento de sua rede de apoio, sendo o grupo um importante recurso para minimizar os impactos psicológicos da restrição da rede de apoio, acentuada pelo distanciamento no cuidador.

A minha filha trabalha em casa agora, trabalha o dia todo, não está nem aí. Meu filho ajuda bastante., só que com a pandemia o que é que eles fizeram: alugaram uma casa no interior [...], eles costumam levar a gente, mas agora não dá mais para levar meu marido junto! Agora eles vão para lá e eu fico aqui. (C1, esposa, 75 anos).

Nesse cenário, o uso das tecnologias para a criação de ambientes virtuais tem demonstrado efeitos positivos, principalmente para aquelas famílias e/ou cuidadores com rede de suporte social limitados ou empobrecidos, de forma a colaborar para a melhoria do bem-estar destes cuidadores, o que foi corroborado em nossa pesquisa (D'Agostino et al., 2020).

Essas reuniōes nos trazem alento, funcionam como um grande abraço caloroso. (C2, esposa, 68 anos).

Essas reuniōes têm me ajudado bastante! Gratidão!. (C4, filha, 47 anos).

E essa questão da gente estar trocando figurinha é muito interessante porque muitas vezes é uma situação que o outro está vivendo e que ele de repente está se espelhando naquilo que você está vivendo. (C6, filho, 49 anos).

O contato social, mesmo que virtual, minimizou os sintomas de depressão, ansiedade e a sensação de solidão, favoreceu o sentimento de pertencimento e possibilitou espaço de troca de experiências e de acolhimento (Chan et al., 2020). 


\section{5a) Nova forma de realizar as atividades significativas}

É extremamente saudável e recomendável que tanto as pessoas com demência quanto seus cuidadores familiares mantenham suas atividades significativas e prazerosas, sejam elas físicas, sociais e/ou de lazer, entre outras. Para que isso ocorra, é necessário que os cuidadores recebam orientaçóes que possam ser aplicadas de forma estratégica e com recursos adequados, de acordo com o nível de comprometimento cognitivo e funcional de cada familiar com demência, a história prévia de atividades e interesses no período de prépandemia da COVID-19. Muitos desses cuidadores não conseguiam adaptar as atividades prévias de seus familiares para serem realizadas dentro do domicílio ou utilizar recursos tecnológicos.

C4 (filha, 47 anos), que cuida do pai com Doença de Parkinson e hidrocefalia de pressão normal e da mãe com demência, referiu oferecer a mesma atividade para ambos e observou que os dois não respondiam da mesma forma, o que a levou a não oferecer mais atividades ao pai.

Os exercicios, minha mãe conseguiu fazer [...] e meu pai não. Eu expliquei, ela explicou e ele não fez. Ele pegava a folha, virava. Então com ela o exercício funciona, com ele já não [...]. (C4, filha, 47 anos).

O grupo proporcionou o acesso às informaçóes sobre como graduar as atividades de estimulação cognitiva, manual e/ou artesanal, de acordo com cada caso, incentivou a troca e o compartilhar de atividades culturais e de lazer, e alimentou nos participantes o desejo de explorar outras formas de fazer. Para tal, eles fizeram uso desde mensagens pelo Whats $A p$, encontros pelo Zoom para realizar passeios virtuais a museus e parques em todo o mundo.

Para os cuidadores, o impacto do distanciamento físico é ainda mais crítico, pois se depararam com um universo novo de responsabilidades diversas e diárias advindas ao longo do processo do cuidar na demência com o agravo da pandemia (Holmes et al., 2020; Schapira et al., 2020). Nesse contexto, tornou-se comum ouvir a expressáo "o novo normal" como a possibilidade de readequar a rotina diária e garantir a realização de atividades de trabalho, de atividades físicas, sociais e culturais durante o cotidiano no formato virtual para manutenção do equilíbrio físico e emocional. Para o cuidador que mora na mesma residência que seu familiar com demência, pode ser que essa realidade náo atinja um mínimo necessário para o equilíbrio mente e corpo. Muitos deles referiram a intrusão ou o atravessamento de suas atividades significativas por seus familiares.

O ponto de equilíbrio é bem complicado, pois quando paro para tentar me direcionar a algo para mim, quase sempre sou interrompido. (C6, filho, 49 anos).

Já para aqueles que prestam auxílio e cuidado a distância ou revezam cuidado, é possível vivenciar e aplicar "o novo normal" em sua rotina diária. A filha cuidadora que reside com sua mãe, mas que recebe o auxílio de uma cuidadora profissional relata: 
Consigo fazer minhas atividades prazerosas... cuido das plantas, assisto filme, caminho com minhas cachorras durante o dia e brinco na internet. (C10, filha, 61 anos).

Observa-se que as questôes sociais, econômicas e demográficas estão indissociáveis à qualidade de vida e de autocuidado dos cuidadores. Isto porque aqueles que têm melhor recursos financeiros podem compensar a ausência de uma rede de suporte efetiva. No entanto, a maioria, até mesmo aqueles com uma rede familiar maior, não tem possibilidade de divisão de tarefas e cuidados de seus pais, ou cônjuges, ficando, assim, sobrecarregados. Dessa forma, é primordial o desenvolvimento de políticas públicas voltadas para as pessoas com demência e seus cuidadores de forma que possam ter seus direitos garantidos pelo estado, principalmente quando não recebem o apoio familiar.

\section{Consideraçóes Finais}

No decorrer dos encontros, problemas como a falta de informação em relação às alteraçóes cognitivas e comportamentais acentuadas no familiar com demência, pouco ou nenhum apoio psicológico diante da sobreposição de demandas, o medo de contaminação de si e dos outros, restrições no espaço domiciliar para conciliar atividades de trabalho e demandas do lar foram relatos frequentes dos cuidadores familiares. Tais demandas, em um ambiente no qual não é possível contar com a sua rede de suporte habitual (parentes, vizinhos/amigos, colaboradores do lar), acarretou a manifestação de comprometimentos psicológicos, como medo, insegurança, culpa, raiva, entre outros do próprio cuidador.

A experiência de apoio virtual se demonstrou recurso potente e que pode ser utilizado como ferramenta para o acesso à informação e às orientaçóes em relação à demência e sobre o cuidado ao familiar com demência, com base nas alteraçóes cognitivas e comportamentais acentuadas com o distanciamento físico. As trocas constantes das vivências comuns entre os cuidadores fortaleceram os vínculos entre eles e foram legitimadas como um espaço de escuta e acolhimento seguro e empático.

Porém, o número restrito de participantes pode limitar as discussóes e possibilidades de generalizaçáo a cuidadores que vivem em diferentes contextos, sejam eles social, econômico, intelectual, cultural e de acesso e de uso dos recursos tecnológicos.

Por meio do grupo de apoio virtual aos cuidadores familiares, foi possível criar possibilidades e estratégias tecnológicas que contemplaram as necessidades desse grupo, com açóes de orientaçôes pontuais, como técnicas de simplificação de comunicaçáo com a pessoa com demência, e orientaçóes mais complexas, quando há a necessidade de orientação quanto ao manejo das alteraçóes comportamentais e psicológicas na demência, além de açóes voltadas para o autocuidado do próprio cuidador com impacto no seu estado emocional e bem-estar, minimizando o sentimento de isolamento social durante a pandemia da COVID-19.

\section{Agradecimentos}

Agradecemos a todos os cuidadores familiares de pessoas com demência pela participação e colaboração. 


\section{Referências}

Allegri, R. F., Sarasola, D., Serrano, C. M., Taragano, F. E., Arizaga, R. L., Butman, J., \& Loñ, L. (2006). Neuropsychiatric symptoms as a predictor of caregiver burden in Alzheimer's disease. Neuropsychiatric Disease and Treatment, 2(1), 105-110.

Alzheimer's Disease International - ADI. (2019). World Alzheimer Report: Attitudes to dementia. London: Alzheimer's Disease International.

American Psychiatric Association - APA (2014). Manual diagnóstico e estatístico de transtornos mentais (DSM5). Porto Alegre: Artmed.

Armitage, R., \& Nellums, L. B. (2020). COVID-19 and the consequences of isolating the elderly. The Lancet Public Health, 5(5), 256.

Bezerra, A. C. V., Silva, C. E. M., Soares, F. R. G., \& Silva, J. A. M. (2020). Fatores associados ao comportamento da população durante o isolamento social na pandemia de COVID-19. Ciência \& Saúde, 25(1), 2411-2421.

Bianchetti, A., Rozzini, R., Guerini, F., Boffelli, S., Ranieri, P., Minelli, G., Bianchetti, L., \& Trabucchi, M. (2020). Clinical Presentation of COVID19 in Dementia Patients. The Journal of Nutrition, Health \& Aging, 24(6), 560-562. http://dx.doi.org/10.1007/s12603-020-1389-1.

Brooks, S. K., Webster, R. K., Smith, L. E., Woodland, L., Wessely, S., Greenberg, N., \& Rubin, G. J. (2020). The psychological impact of quarantine and how to reduce it: rapid review of the evidence. Lancet, 395(102227), 912-920. http://dx.doi.org/10.1016/S0140-6736(20)30460-8.

Camacho, A. C. L. F., Thimoteo, R. S., \& Souza, V. M. F. (2020). Information technology for the elderly in times of COVID-19. Research Social Development, 9(6), 1-10.

Caramelli, P., \& Bottino, C. M. C. (2007). Tratando os Sintomas Comportamentais e Psicológicos da demência (SCPD). Jornal Brasileiro de Psiquiatria, 56(2), 83-87.

Chan, E., Gobat, N., Kim, J. H., Newnham, E. A., Huang, Z., Hung, H., Dubois, C., Hung, K., Wong, E., \& Wong, S. (2020). Informal home care providers: the forgotten health-care workers during the COVID-19 pandemic. Lancet, 395(10242), 1957-1959. http://dx.doi.org/10.1016/S01406736(20)31254-X.

Cuffaro, L., Di Lorenzo, F., Bonavita, S., Tedeschi, G., Leocani, L., \& Lavorgna, L. (2020). Dementia care and COVID-19 pandemic: a necessary digital revolution. Neurological Sciences, 41(8), 1977-1979. http://dx.doi.org/10.1007/s10072-020-04512-4.

D’Agostino, A., Demartini, B., Cavallotti, S., \& Gambini, O. (2020). Mental health services in Italy during the COVID-19 outbreak. Lancet, 7(5), 385-387.

Engedal, K., \& Laks, J. (2016). Towards a Brazilian dementia plan? Lessons to be learned from Europe. Dementia \& Neuropsychologia, 10(2), 74-78.

Holmes, E. A., O’Connor, R. C., Perry, V. H., Tracey, I., Wessely, S., Arseneault, L., Ballard, C., Christensen, H., Cohen Silver, R., Everall, I., Ford, T., John, A., Kabir, T., King, K., Madan, I., Michie, S., Przybylski, A. K., Shafran, R., Sweeney, A., Worthman, C. M., \& Bullmore, E. (2020). Multidisciplinary research priorities for the COVID-19 pandemic: a call for action for mental health science. The Lancet Psychiatry, 7(6), 547-560. http://dx.doi.org/10.1016/S2215-0366(20)30168-1.

Huali, W., Li, T., Barbarino, P., Gauthier, S., Brodaty, H., Molinuevo, J. L., Xie, H., Sun, Y., Yu, E., Tang, Y., Weidner, W., \& Yu, X. (2020). Dementia care during COVID-19. Lancet, 395(10231), 1190-1191. http://dx.doi.org/10.1016/S0140-6736(20)30755-8.

Jiménez, L., Guerrero, A., Becerra, J. C., Herrera, J. F. M., Benavides, A., Estrada, E., Rugeles, J. G., Restrepo, D., Tamayo, J., Castaño, K., Benjumea, P., Londońo, M., Galvis, N. D., Valenzuela, L. F., Arango, G., Zuluaga, M., Beltrán, D. S., Gelvis, G., Echeverría, M. C., Rojas, J., Forero, L., Rincón, G., Acosta, M. F., Lema, S., Briceño, F. A., Gómez, D. C., Saavedra, A. M., Castellanos-Perilla, N., Tobón, C., Lopera, F., Cano, C., Garcia-Cifuentes, E., \& Aguillon, D. (2019). Decálogo de recomendaciones para personas con deterioro cognitivo - demencia y sus cuidadores en el contexto del aislamiento social obligatorio por la pandemia por SARS-COV-2 2020. Medellín: Universidad de Antioquia. Recuperado em 18 de junho de 2020, de https://www.researchgate.net/publication/340715990_Decalogo_de_recomedaciones_para_personas_con_ 
deterioro_cognitivo_-

demencia_y_sus_cuidadores_en_el_contexto_del_aislamiento_social_obligatorio_por_la_pandemia_por_S ARS-COV-2

Júnior, A. R. T., \& Souza, C. C. (2017). Sintomas comportamentais e psicológicos nas demências. In E.V. Freitas \& L. Py (Eds.), Tratado de geriatria e gerontologia (pp. 899-945). Rio de Janeiro: Guanabara Koogan.

Kontoagelos, K., Economou, M., \& Papageorgiou, C. (2020). Mental Health Effects of COVID-19 Pandemia: A review of clinical and psychological traits. Psychiatry Investigation, 17(6), 491-505.

Levy, L. L., \& Burns, T. (2011). The cognitive disabilities reconsidered model: Rehabilitation of adults with dementia. In Katz N. (Ed.), Cognition, occupation, and participation across the life span: Neuroscience, neurorehabilitation, and models of intervention in occupational therapy (pp. 407-441). Bethesda: American Occupational Therapy Association.

Lyketsos, C. G., Carrillo, M. C., Ryan, J. M., Khachaturian, A. S., Trzepacz, P., Amatniek, J., Cedarbaum, J., Brashear, R., \& Miller, D. S. (2011). Neuropsychiatric symptoms in Alzheimer's disease. Alzheimer's హD Dementia, 7(5), 532-539. http://dx.doi.org/10.1016/j.jalz.2011.05.2410.

Mattos, E. B. T., \& Kovács, M. J. (2020). Doença de Alzheimer: a experiência única de cuidadores familiares. Psicologia USP, 31, e180023. http://dx.doi.org/10.1590/0103-6564e180023.

Minayo, M. C. S. (2015). O desafio do conhecimento: pesquisa qualitativa em saúde. São Paulo: Hucitec Editora.

Ministério da Saúde (2020). Brasil confirma primeiro caso da doença. Recuperado em 15 de outubro de 2020, de https://www.gov.br/saude/pt-br

Morin, E. (2003). Introdução ao pensamento complexo. Lisboa: Piaget.

Organização Pan-Americana da Saúde - OPAS. (2020). Folha informativa - COVID-19 (doença causada pelo novo coronavirus). Recuperado em 15 de outubro de 2020, de https://www.paho.org/pt/covid19

Prince, M., Bryce, R., Albanese, E., Wimo, A., Ribeiro, W., \& Ferri, C. P. (2013). The global prevalence of dementia: a systematic review and metaanalysis. Alzheimer's \& Dementia, 9(1), 63-75.

http://dx.doi.org/10.1016/j.jalz.2012.11.007.

Schapira, M., Cohen, G., Guajardo, M. E., Martinez, D., Schapira, M., Seinhart, B. D., \& Soderlund, M. E. (2020). Reflexiones sobre vivir con demencia en épocas del COVID-2019. Rev. Archives of Gerontology and Geriatrics, 34(1), 19-20.

Selbaek, G., Kirkevold, Ø., \& Engedal, K. (2007). The prevalence of psychiatric symptoms and behavioural disturbances and the use of psychotropic drugs in Norwegian nursing homes. International Journal of Geriatric Psychiatry, 22(9), 843-849. http://dx.doi.org/10.1002/gps.1749.

\section{Contribuição dos Autores}

Emanuela Bezerra Torres Mattos: Concepção do texto, análise do material coletado, redação do texto e revisão final. Isabela da Costa Francisco: Concepção do texto, Redação do texto e revisão final. Gabrielle Christine Pereira: Concepção do texto, Redaçáo do texto e revisão final. Marcia Maria Pires Camargo Novelli: Redação do texto e revisão final. Todas as autoras aprovaram a versáo final do artigo. 


\section{Fonte de Financiamento}

Este trabalho recebeu auxílio financeiro do Programa

Institucional de Bolsas de Extensão - PIBEX, da

Universidade Federal de São Paulo.

\section{Autora para correspondência}

Emanuela Bezerra Torres Mattos

e-mail: emattos@unifesp.br

\section{Editora de seçáo}

Profa. Dra. Iza Faria-Fortini 